\title{
Preparation and Crystal Structure of $\mathrm{MnBiSe}_{2} \mathrm{I}$
}

\author{
Arno Pfitzner*, Manfred Zabel, and Franz Rau \\ Regensburg, Institut für Anorganische Chemie der Universität \\ Received February 18th, 2005. \\ Dedicated to Professor Gerd Becker on the Occasion of $65^{\text {th }}$ Birthday
}

\begin{abstract}
Black single crystals of $\mathrm{MnBiSe}_{2} \mathrm{I}$ were obtained by the reaction of stoichiometric amounts of $\mathrm{Mn}, \mathrm{Bi}, \mathrm{BiI}_{3}$, and $\mathrm{Se}$ at $600{ }^{\circ} \mathrm{C}$ for 7 days. The compound crystallizes in the monoclinic system, space group $C 2 / m$, with $a=13.428(2), b=4.112(1), c=$ $10.130(2) \AA, \beta=90.97(2)^{\circ}$, and $Z=4$. The crystal structure refinement based on 849 reflections converged at $R=0.0380$ and $w R 2=$
\end{abstract}

0.0916, respectively. $\mathrm{MnBiSe}_{2} \mathrm{I}$ forms a layer structure consisting of $\mathrm{MnSe}_{6}$ octahedra, $\mathrm{MnSe}_{2} \mathrm{I}_{4}$ octahedra, and $\mathrm{BiSe}_{3+2}$ pyramids.

Keywords: Manganese; Bismuth; Selenium; Iodine; Sulfosalts; Crystal structure

\section{Introduction}

The synthesis of layered materials with interesting magnetic properties on the basis of transition elements usually is focussed on iron, chromium, and manganese containing compounds. A mineral related group of compounds containing these ions are the so-called sulfo salts, e.g. $\mathrm{FeSb}_{2} \mathrm{~S}_{4}$ (berthierite) [1]. Inspired by a publication dealing with a layered material of this composition, namely $\mathrm{MnBi}_{2} \mathrm{~S}_{4}$ [2], we recently started to elucidate the existence of further sulfo salts of $\mathrm{Mn}^{2+}$, which usually occurs as a $d^{5}$ high spin ion in octahedral environment in these compounds. It was shown that $\mathrm{MnSb}_{2} \mathrm{~S}_{4}$ can be obtained either by hydrothermal methods as an orthorhombic compound which is isotypic to $\mathrm{FeSb}_{2} \mathrm{~S}_{4}$ [3], i.e. oP28, or by solid state reactions as a monoclinic phase $m C 28$ which is closely related to $\mathrm{MnBi}_{2} \mathrm{~S}_{4}$ [4]. The homologous $\mathrm{MnSb}_{2} \mathrm{Se}_{4} m C 28$ could also be obtained by solid state preparation [5]. Spin polarized DFT calculations confirmed the semiconducting behaviour of both phases of $\mathrm{MnSb}_{2} \mathrm{~S}_{4}[5,6]$. Neutron powder diffraction experiments on $\mathrm{MnSb}_{2} \mathrm{~S}_{4} m C 28$ and the heavier homologous compounds revealed that these compounds become antiferromagnetic below about $25 \mathrm{~K}$. The magnetic spins show a complicated helical ordering pattern [5, 7]. Manganese ions are octahedrally coordinated by chalcogenide ions in these materials. The $\mathrm{MnQ}_{6}$ octahedra $(\mathrm{Q}=\mathrm{S}, \mathrm{Se})$ share common edges to give strands of octahedra along one crystallographic direction. These strands of octahedra are interlinked by chalcogenometalate ions to form layers, which are stacked above each other with weak interlayer interactions [4]. It is interesting to prepare new layered magnetic materi-

\footnotetext{
* Prof. Dr. A. Pfitzner

Institut für Anorganische Chemie

Universität Regensburg

D-93040 Regensburg (Germany)

Fax: +49 9419434983

E-mail: arno.pfitzner@chemie.uni-regensburg.de
}

als by changing the connectivity of these strands of octahedra by chemical modification of the compounds. Thus, new ordering patterns of the spins can be expected. One way how to change the connectivity is the partial substitution of chalcogenide ions by halide ions. Two examples for such compounds were recently described: monoclinic $\mathrm{MnSbSe}_{2} \mathrm{I} m C 20$ [8] and orthorhombic $\mathrm{MnSbS}_{2} \mathrm{Cl} o P 20$ [9]. The different radii of the constituting ions have obviously a certain influence on the structural arrangement of the resulting compounds. Thus, we find two different types of octahedra $\mathrm{MnSe}_{6}$ and $\mathrm{MnSe}_{2} \mathrm{I}_{4}$ in $\mathrm{MnSbSe}_{2} \mathrm{I}$ but only one type of octahedra $\mathrm{MnS}_{4} \mathrm{Cl}_{2}$ in $\mathrm{MnSbS}_{2} \mathrm{Cl}$. The different octahedra in $\mathrm{MnSbSe}_{2} \mathrm{I}$ share common edges formed either by two Se atoms or by two I atoms, respectively,. In contrast, only common edges formed by one $\mathrm{S}$ and one $\mathrm{Cl}$ atom are found in $\mathrm{MnSbS}_{2} \mathrm{Cl}$. These strands of octahedra share common $\mathrm{Q}$ vertices in $\mathrm{MnSbSe}_{2} \mathrm{I}$ and also in $\mathrm{MnSbS}_{2} \mathrm{Cl}$. The introduction showed up the close relations of $\mathrm{MnSb}_{2} \mathrm{Q}_{4}$ and $\mathrm{MnBi}_{2} \mathrm{Q}_{4}$. Thus, we prepared the heavier homologous compound $\mathrm{MnBiSe}_{2} \mathrm{I}$ and determined the crystal structure in order to further check the influence of the different ionic radii on the observed crystal structures.

\section{Results}

\section{Structure determination}

Single crystals of the title compound suitable for a structure determination could be obtained from different synthetic routes, see the experimental section for details. X-ray intensities were collected on a STOE IPDS-I using MoK $\alpha$ radiation, $\lambda=0.71073 \AA$. The compound crystallizes in the monoclinic system with the lattice constants $a=13.428(2)$, $b=4.112(1), c=10.130(2) \AA, \quad \beta=90.97(2)^{\circ}, \quad V=$ 559.3(1) $\AA^{3}$, and $Z=4$. The space group $C 2 / m$ was derived from systematic extinctions and confirmed by the subsequent refinement. Direct methods were applied to solve the structure and provided the positions of one $\mathrm{Bi}$, one I, two Se and two Mn atoms. The refinement converged at 
$R=0.0359$ for reflections with $I>2 \sigma_{I}$ and $R=0.0380$ for all reflections. A total of 849 independent reflections was used for the refinement of 34 parameters. Anisotropic displacement parameters were used for all atoms. An extinction parameter was included in the last refinement cycles. Further crystallographic details are summarized in Table 1. Atomic coordinates and anisotropic displacement parameters are collected in Table 2 and Table 3, respectively. Table 4 contains selected interatomic distances and angles calculated from these data.

Table 1 Crystallographic data for the structure analysis of $\mathrm{MnBiSe}_{2} \mathrm{I}$

\begin{tabular}{|c|c|}
\hline Compound & $\mathrm{MnBiSe}_{2} \mathrm{I}$ \\
\hline Formula weight in $\mathrm{g} \mathrm{mol}^{-1}$ & 548.74 \\
\hline Crystal size in $\mathrm{mm}^{3}$ and colour & $0.1 \times 0.1 \times 0.07$, black \\
\hline Crystal system & monoclinic \\
\hline Space group & $C 2 / m$ (No. 12$)$ \\
\hline Lattice constants in $\AA$ & $a=13.428(2)$ \\
\hline \multirow[t]{3}{*}{ from single crystal } & $b=4.112(1)$ \\
\hline & $c=10.130(2)$ \\
\hline & $\beta=90.97(2)^{\circ}$ \\
\hline Cell volume, $\mathrm{Z}$ & $559.3(1) \AA^{3}, 4$ \\
\hline$\rho_{\text {calc }}$ in $\mathrm{g} \mathrm{cm}^{-3}$ & 6.517 \\
\hline Diffractometer & $\begin{array}{l}\text { STOE IPDS-I, MoK } \alpha, \lambda=0.71073 \AA \text {, } \\
\text { oriented graphite monochromator }\end{array}$ \\
\hline$\varphi$-range in ${ }^{\circ}, \Delta \varphi$ in $^{\circ}$ & $0.0 \leq \varphi \leq 191.8,1.4$ \\
\hline$\mu(\mathrm{MoK} \alpha)$ in $\mathrm{mm}^{-1}$ & 52.05 \\
\hline Absorption correction & $\begin{array}{l}\text { numerical, crystal description with } 7 \text { faces, } \\
\text { shape optimizes with X-SHAPE [10] }\end{array}$ \\
\hline No. of measured images & 137 \\
\hline Irradiation time/image in min & 8 \\
\hline Temperature in ${ }^{\circ} \mathrm{C}$ & 20 \\
\hline $2 \theta$-range in ${ }^{\circ}$ & $4.2 \leq 2 \theta \leq 58.6$ \\
\hline$h k l$-range & $-16 \leq h \leq 18$ \\
\hline & $-5 \leq k \leq 5$ \\
\hline & $-13 \leq 1 \leq 13$ \\
\hline No. of reflections, $R_{\text {int }}$ & $2875,0.0463$ \\
\hline No. of independent reflections & 849 \\
\hline No. of parameters & 34 \\
\hline Program & SHELX 97 [11] \\
\hline Final $R / w R\left(I>2 \sigma_{I}\right)$ & $0.0359,0.0906$ \\
\hline Final $R / w R$ (all reflections) & $0.0380,0.0916$ \\
\hline GooF & 1.054 \\
\hline Largest difference peak $\Delta \rho_{\max }$ & 2.238 \\
\hline and hole $\Delta \rho_{\min }$ in $\mathrm{e}^{-3}$ & -1.772 \\
\hline
\end{tabular}

Further details of the crystal structure investigations are available from the Fachinformationszentrum Karlsruhe, D-76344 Eggenstein-Leopoldshafen (Germany), Fax: 00497247808 666, E-mail: crysdata@fiz-karlsruhe.de, on quoting the depository number CSD-415138, the name of the authors, and the reference of the publication.

Table 2 Atomic coordinates and equivalent isotropic displacement parameters $\mathrm{U}_{\text {eq }}$ in $\AA^{2}$ for $\mathrm{MnBiSe}_{2} \mathrm{I}$

\begin{tabular}{lllll}
\hline Atom & $x$ & $y$ & $z$ & $U_{\mathrm{eq}}{ }^{\mathrm{a}}$ \\
\hline $\mathrm{Bi}$ & $0.2092(1)$ & 0 & $0.8102(1)$ & $0.024(1)$ \\
$\mathrm{Mn} 1$ & 0 & $1 / 2$ & 0 & $0.024(1)$ \\
$\mathrm{Mn} 2$ & 0 & $1 / 2$ & $1 / 2$ & $0.025(1)$ \\
$\mathrm{I}$ & $0.1371(1)$ & 0 & $0.4266(1)$ & $0.024(1)$ \\
$\mathrm{Se} 1$ & $0.1364(1)$ & 0 & $0.0570(1)$ & $0.020(1)$ \\
$\mathrm{Se} 2$ & $0.0714(1)$ & $1 / 2$ & $0.7559(1)$ & $0.020(1)$ \\
\hline
\end{tabular}

${ }^{\text {a }} U_{\text {eq }}$ is defined as one third of the trace of the orthogonalized $U_{\mathrm{ij}}$ tensor.

\section{Structure description and discussion}

$\mathrm{MnBiSe}_{2} \mathrm{I}$ crystallizes isotypic with $\mathrm{MnSbS}_{2} \mathrm{I}$. The coordination spheres of the metal ions are shown in Figure 1.
Table 3 Anisotropic displacement parameters $U_{i j}$ in $\AA^{2}$ for $\mathrm{MnBiSe}_{2} \mathrm{I}$. $\mathrm{U}_{12}=\mathrm{U}_{23}=0$

\begin{tabular}{llllr}
\hline Atom & $U_{11}$ & $U_{22}$ & $U_{33}$ & \multicolumn{1}{c}{$U_{13}$} \\
\hline Bi & $0.024(1)$ & $0.023(1)$ & $0.024(1)$ & $0.004(1)$ \\
Mn1 & $0.024(1)$ & $0.024(1)$ & $0.023(1)$ & $0.004(1)$ \\
Mn2 & $0.026(1)$ & $0.023(1)$ & $0.026(1)$ & $0.001(1)$ \\
I & $0.022(1)$ & $0.022(1)$ & $0.028(1)$ & $0.004(1)$ \\
Se1 & $0.020(1)$ & $0.021(1)$ & $0.020(1)$ & $0.000(1)$ \\
Se2 & $0.022(1)$ & $0.019(1)$ & $0.020(1)$ & $-0.001(1)$ \\
\hline
\end{tabular}

Table 4 Selected interatomic distances (in $\AA$ ), and angles (in degrees) for $\mathrm{MnBiSe}_{2} \mathrm{I}$ at room temperature

\begin{tabular}{|c|c|c|c|c|c|}
\hline Bi-Se1 & & $2.700(1)$ & Sel-Bi-Se1 & & 79.94(3) \\
\hline $\mathrm{Bi}-\mathrm{Se} 2$ & $2 x$ & $2.8140(8)$ & Se1-Bi-Se1 & $2 x$ & $81.55(3)$ \\
\hline \multirow[t]{2}{*}{ Bi-Se1 } & $2 x$ & $3.201(1)$ & Se1-Bi-Se2 & $2 x$ & $86.22(3)$ \\
\hline & & & Se2-Bi-Se1 & $2 x$ & $91.83(2)$ \\
\hline $\mathrm{Mn} 1-\mathrm{Se} 2$ & $2 x$ & $2.667(1)$ & $\mathrm{Se} 2-\mathrm{Bi}-\mathrm{Se} 2$ & & $93.89(4)$ \\
\hline \multirow[t]{2}{*}{ Mn1-Se1 } & $4 x$ & $2.8069(8)$ & Se2-Bi-Se1 & $2 x$ & $166.12(3)$ \\
\hline & & & Se1-Mn1-Se1 & $2 x$ & 180 \\
\hline Mn2-I & $4 x$ & $2.8666(6)$ & $\mathrm{Se} 2-\mathrm{Mn} 1-\mathrm{Se} 2$ & & 180 \\
\hline \multirow[t]{12}{*}{$\mathrm{Mn} 2-\mathrm{Se} 2$} & $2 x$ & $2.748(1)$ & Se1-Mn1-Se1 & $2 x$ & $85.80(3)$ \\
\hline & & & Se1-Mn1-Se2 & $4 x$ & $86.98(3)$ \\
\hline & & & Se1-Mn1-Se2 & $4 x$ & $93.02(3)$ \\
\hline & & & Se1-Mn1-Se1 & $2 x$ & $94.20(3)$ \\
\hline & & & I-Mn2-I & $2 x$ & 180 \\
\hline & & & $\mathrm{Se} 2-\mathrm{Mn} 2-\mathrm{Se} 2$ & & 180 \\
\hline & & & Se2-Mn2-I & $4 x$ & $88.32(3)$ \\
\hline & & & I-Mn2-I & $2 x$ & $88.34(2)$ \\
\hline & & & I-Mn2-I & $2 x$ & $91.66(2)$ \\
\hline & & & Se2-Mn2-I & $4 x$ & $91.68(3)$ \\
\hline & & & Mn2-I-Mn2 & & $91.66(2)$ \\
\hline & & & Mn1-Se2-Mn2 & & $138.52(5)$ \\
\hline
\end{tabular}

a)

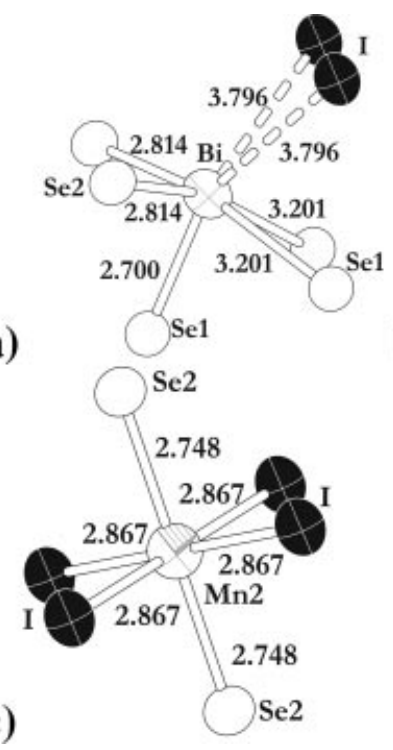

b)

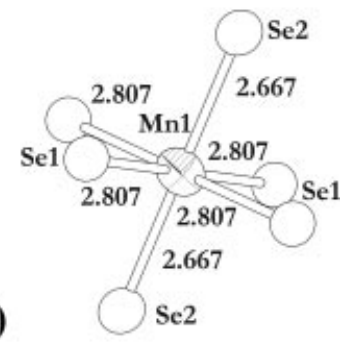

Figure 1 Coordination spheres of the metal ions in $\mathrm{MnBiSe}_{2} \mathrm{I}$, distances are given in $\AA$. Displacement parameters are drawn at the $95 \%$ probability level.

The bismuth atom is exclusively coordinated by Se atoms in its first coordination sphere. As shown by the distances and angles the coordination of Bi towards Se can be regarded as $3+2$, i.e. we find the typical arrangement for 


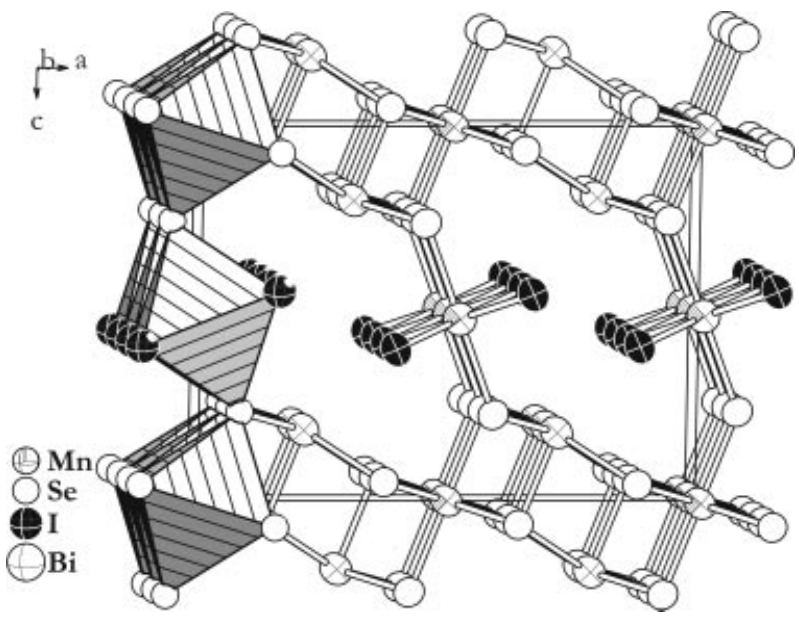

Figure 2 Section of the crystal structure of $\mathrm{MnBiSe}_{2} \mathrm{I}$. Mn atoms are octahedrally coordinated and the octahedra form chains along $b$. $\mathrm{BiSe}_{3+2}$ units connect the chains to form layers parallel (001).

sulfo salts. Three short bonds $d(\mathrm{Bi}-\mathrm{Se})$ are in the range from $2.700-2.814 \AA$, and two medium range bonds $d(\mathrm{Bi}-\mathrm{Se})=$ $3.201 \AA$ are found. Two iodine atoms are located in a long distance $d(\mathrm{Bi}-\mathrm{I})=3.796 \AA$. These distances $d(\mathrm{Bi}-\mathrm{I})$ are much longer than those found in $\mathrm{BiI}_{3}, d(\mathrm{Bi}-\mathrm{I}) \leq 3.124 \AA$ [12]. Manganese ions are six-coordinate, either only by selenide ions or by four iodide ions and two selenium ions. Both types of octahedra show two short axial bonds, i.e. $d(\mathrm{Mn}-\mathrm{Se} 2)=2.667 \AA$ for $\left[\mathrm{MnSe}_{6}\right]$ and $d(\mathrm{Mn}-\mathrm{Se} 2)=$ $2.748 \AA$ for $\left[\mathrm{MnSe}_{2} \mathrm{I}_{4}\right]$. The distances in the basal plane are longer, namely $d(\mathrm{Mn}-\mathrm{Se} 1)=2.807 \AA$ for $\left[\mathrm{MnSe}_{6}\right]$ and $d(\mathrm{Mn}-\mathrm{I})=2.867 \AA$ for $\left[\mathrm{MnSe}_{2} \mathrm{I}_{4}\right]$. Having the connectivity of the octahedra in mind, one finds a compression along the direction of the common vertices Se2, i.e. [001]. The longer bonds are found in the direction of the chains of octahedra, i.e. [010], see Figure 2.

The distances of the manganese atom to the surrounding atoms are similar to those found in the isotypic compound $\mathrm{MnSbSe}_{2} \mathrm{I}$ [8]. Obviously the monoclinic structure type is preferred for the present combination of elements. The volumes of the unit cells of $\mathrm{MnSbSe}_{2} \mathrm{I}\left(V=543 \AA^{3}\right)$ and of $\mathrm{MnBiSe}_{2} \mathrm{I}\left(V=559 \AA^{3}\right)$ differ only slightly, especially when the measuring temperature of $153 \mathrm{~K}$ for $\mathrm{MnSbSe}_{2} \mathrm{I}$ is taken into account. The same is found for the couple $\mathrm{MnSb}_{2} \mathrm{~S}_{4}$ $\left(V=669 \AA^{3}\right)$ and $\mathrm{MnBi}_{2} \mathrm{~S}_{4}\left(V=672 \AA^{3}\right)$. Obviously the volume which is occupied by the tri-valent cations $\mathrm{Sb}^{3+}$ and $\mathrm{Bi}^{3+}$ is almost the same. This is probably due to the fact that the difference between short bonds Sb-Q and long bonds $\mathrm{Sb}-\mathrm{Q}$ (the so-called non bonding distances) is much bigger than in case of $\mathrm{Bi}-\mathrm{Q}$, where these distances are evened out to a certain degree. In case of $\mathrm{MnSbS}_{2} \mathrm{Cl}$ [9] the bonds $\mathrm{Mn}-\mathrm{Cl}$ are significantly shorter than the bonds Mn-S. This results in a modified coordination behaviour of the manganese atoms and a completely different three dimensional crystal structure is formed. At the moment $\mathrm{MnBiS}_{2} \mathrm{Br}$ is under investigation and this compound is also isotypic with $\mathrm{MnBiSe}_{2} \mathrm{I}$ and $\mathrm{MnSbSe}_{2} \mathrm{I}$, due to similarly long bonds $\mathrm{Mn}-\mathrm{Br}$ as compared to $\mathrm{Mn}-\mathrm{S}$. In this case the monoclinic angle $\beta=90.87^{\circ}$ is even closer to $90^{\circ}$ than in $\mathrm{MnBiSe}_{2} \mathrm{I}[13]$

\section{Experimental Section}

$\mathrm{MnBiSe}_{2} \mathrm{I}$ was obtained either by reaction of stoichiometric amounts of $\mathrm{Mn}, \mathrm{BiI}_{3}, \mathrm{Bi}$, and $\mathrm{Se}(3: 1: 2: 6)$ or by reaction of $\mathrm{Mn}_{3} \mathrm{Bi}_{2} \mathrm{Se}_{6}$ with $\mathrm{BiI}_{3}(1: 1)$. Both reaction mixtures were sealed in evacuated quartz ampoules and then heated to $600{ }^{\circ} \mathrm{C}$ for 7 days. The title compound was isolated as black shiny needle shaped crystals. However, in both cases no phase pure product could be obtained. The by-products could not yet be identified in detail. However, MnSe is always one of the impurities.

X-ray powder diffraction patterns were recorded on a Stoe STADI $\mathrm{P}$ running with germanium monochromatized $\mathrm{CuK} \alpha_{1}$ radiation. Single crystals were fixed on thin walled glass capillaries and then mounted on a Stoe IPDS single crystal diffractometer providing monochromatic MoK $\alpha$ radiation. Crystallographic data are collected in Table 1. Absorption was corrected after the optimization of the description of the crystal shape with the X-SHAPE routine [10].

Acknowledgement. Financial support of the University of Regensburg and the State of Bavaria is gratefully acknowledged. We thank Fabian Dielmann for some experimental help.

\section{References}

[1] M. J. Buerger, Th. Hahn, Am. Miner. 1950, 40, 226.

[2] S. Lee, E. Fischer, J. Czerniak, N. Nagasundaram, J. Alloys Compds. 1993, 197, 1.

[3] K. Bente, A. Edenharter, Z. Kristallogr. 1989, 186, 31.

[4] A. Pfitzner, D. Kurowski, Z. Kristallogr. 2000, 215, 373.

[5] D. Kurowski, Ph.D. thesis, Universität Regensburg, 2003.

[6] S. F. Matar, R. Weihrich, D. Kurowski, A. Pfitzner, submitted.

[7] D. Kurowski, A. Pfitzner, W. Kockelmann, M. H. Möller, R. Pöttgen, in preparation.

[8] O. Tourgait, J. A. Ibers, A. Mar, Acta Crystallogr. 2003, C59, i77.

[9] C. Doussier, P. Léone, Y. Moëlo, Solid State Sci. 2004, 6, 1387.

[10] X-SHAPE, STOE, Darmstadt 1996.

[11] G. M. Sheldrick, SHELX 97 Programs for the solution and refinement of crystal structures, University of Göttingen, Germany, 1997.

[12] M. Ruck, Z. Kristallogr. 1995, 210, 650.

[13] A. Pfitzner, M. Zabel, F. Rau, Monatsh. Chem., in press. 